SUCCESS FOR BDA TRAINING ESSENTIALS

The British Dental Association (BDA) Events team are delighted that 346 people have already attended 12 of their new Training essentials sessions. Launched earlier this year, the Training essentials portfolio of courses represented a new direction for the team, but take up and feedback have been very positive.

Multiple practice managers praised the Maximise your team's potential course with over half highlighting the sessions on appraisals as extremely useful.

'Well balanced, clear and informative,' said a dental hygienist from Wimbledon of the IRMER course in radiography and radiation protection. 'Eric Whaites [the speaker] made the day very stimulating.'
Delegates also gave feedback to the BDA about what courses they would like to see in the future. As a result, the Events team has added seven new courses including: reception and telephone skills for the dental team; assertiveness at work; growing and promoting your practice; and achieving high standards in infection control.

The Training essentials portfolio now covers all five core CPD topics recommended by the General Dental Council (GDC).

Many of the new courses will now be provided in both London and Manchester, and several in Edinburgh and Bristol.

Information about the BDA's Training essentials and about discounted hotel rates can be found at www.bda.org/training or by telephoning 02075634590 .

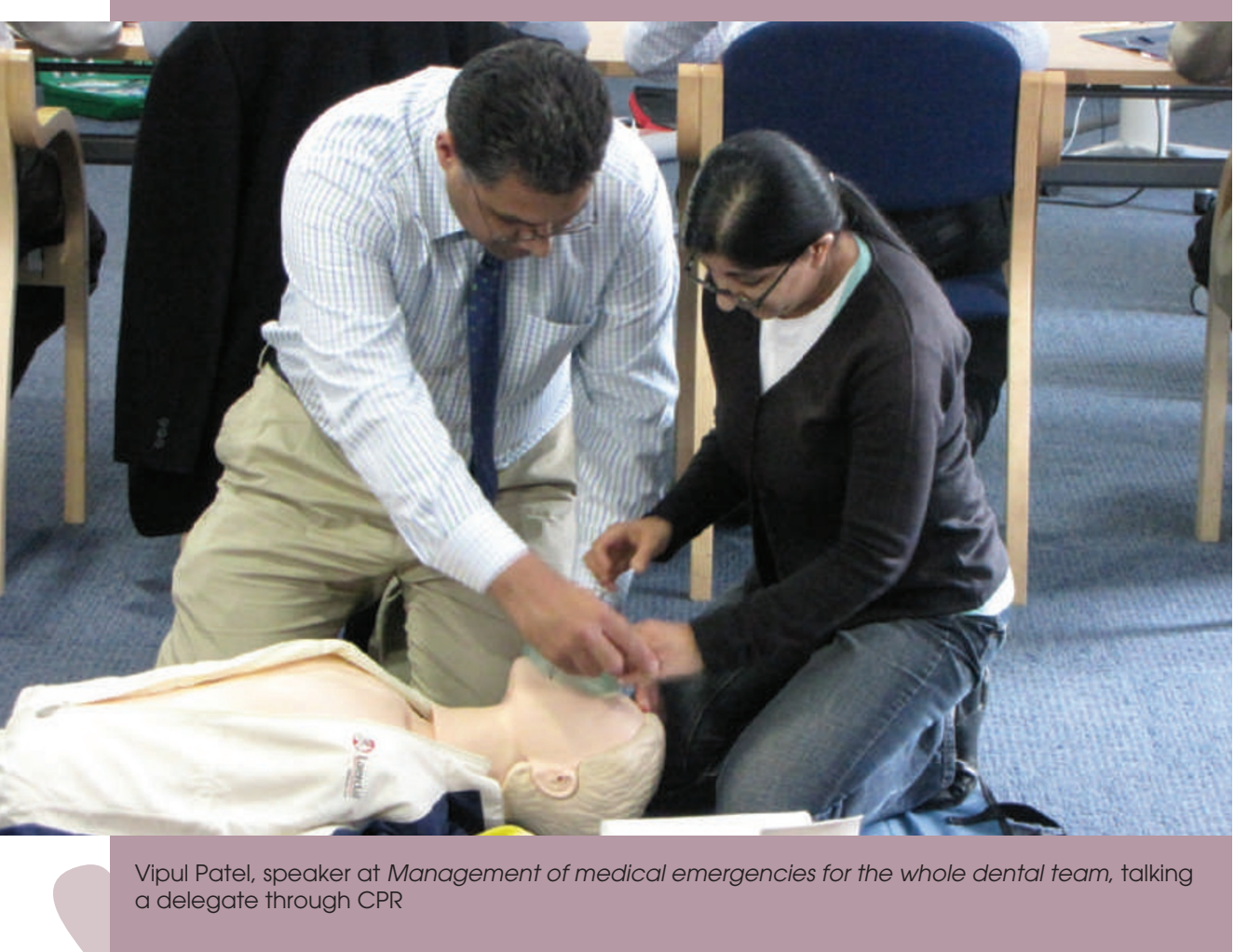

\title{
DRESS WELL TO SAVE ON TAX
}

Dental practice owners who provide their reception staff with uniforms should make sure that each garment bears the practice logo or name. According to tax legislation, unless there is a logo or name on each part of the uniform, it will be treated as a benefit in kind. The National Association of Specialist Dental Accountants (NASDA) is alerting the dental profession to the legislation as Her Majesty's Revenue and Customers (HMRC) tax inspectors who carry out dental practice inspections may ask about reception staff uniforms.

Uniforms bought by the employer and not worn for protection, such as dental nurse tunics, are automatically subject to tax at the full value unless there is a name or logo embroidered onto each garment. HMRC carries out occasional spot checks, and tax inspectors are also likely to ask whether team members are getting free dental treatment. This is also deemed to be a benefit in kind. Exposing the practice's logo or name on staff uniforms should also help promote the practice's brand and have a positive impact on patients.

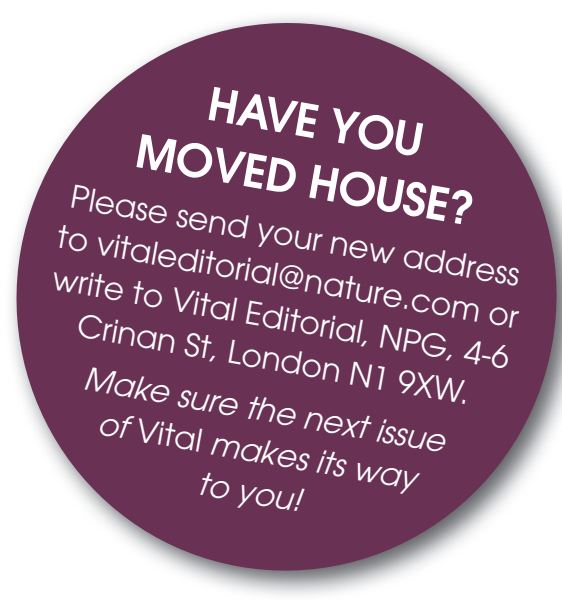

\section{OVER 3,000 FAIL TO PAY ARF}

Three thousand, three hundred and eighty-seven DCPs have been removed from the GDC register after failing to pay the Annual Retention Fee (ARF) by 31 July 2010.

Those DCPs who want to return to the register can complete a form to apply for restoration. A medical examination, character reference, evidence of having completed the required amount of continuing professional development (CPD) and a fee of $£ 120$ are required to apply for restoration. If the DCP was practising overseas or working in the UK while their name was erased from the register, they and their employer will need to explain the circumstances in a letter. Further information can be found at www.gdc-uk.org or by telephoning 08452224141.

\section{HUGE RISE IN DENTAL NURSE APPRENTICE FIGURES}

The fastest year-on-year growth in health apprenticeship numbers in 2008-2009 was among pharmacy technicians and dental nurses, according to new figures published by Skills for Health.

The number of people beginning health apprenticeships in England overall has risen by nearly a third. Total new starts reached 3,096 in 2008-2009, compared to 2,230 in 20072008 , an increase of $28 \%$.

The increase in pharmacy technician and dental nurse apprenticeships follow the introduction of statutory regulation for both occupational groups, which is believed to have encouraged more trainees to follow an apprenticeship as a means of acquiring professional accreditation.

'These figures show that more and more employers are realising that apprenticeships offer a realistic workforce development solution which supports new ways of delivering services and improving patient care,' said John Rogers, Skills for Health chief executive. 